\title{
Chapter 7 \\ Perspectives on Pliocene and Pleistocene Pedal Patterns and Protection
}

\section{Implications for Footprints}

\author{
Erik Trinkaus, Tea Jashashvili, and Biren A. Patel
}

\begin{abstract}
As a framework for interpreting Pliocene and Pleistocene hominin footprints, the functional implications of australopith and Homo pedal remains are reviewed. Despite minor variations in pedal proportions and articular morphology, all of these remains exhibit tarsometatarsal skeletons fully commensurate with an efficient (human) striding bipedal gait. The Middle and Late Pleistocene Homo pedal phalanges exhibit robust and distally flattened metatarsal 1 heads, hallux valgus, relatively short lateral digits with largely straight proximal phalanges with dorsally oriented metatarsal facets, all similar to those of recent humans. The Pliocene and Early Pleistocene halluces lack hallux valgus and have bulbous metatarsal 1 heads. The australopith pedal remains have lateral proximal phalanges that are relatively long and dorsally curved and have more proximally oriented metatarsal facets. In addition, pre-Upper Paleolithic Homo lateral phalanges have robust diaphysis implying the habitual absence of protective footwear, whereas the Upper Paleolithic ones are variably gracile, especially at higher latitudes, indicating more consistent use of footwear. These paleontological considerations provide a framework for interpreting the distal portions of earlier hominin footprints (especially with respect to hallucal orientation and digital length) and suggest that many of the Late Pleistocene footprints may be unrecognized given the use of footwear.
\end{abstract}

\footnotetext{
E. Trinkaus $(\bowtie)$

Department of Anthropology, Washington University, Saint Louis, MO, USA

e-mail: trinkaus@wustl.edu

T. Jashashvili

Department of Integrative Anatomical Sciences, Keck School of Medicine, University of Southern California, Los Angeles, CA, USA

Department of Geology and Paleontology, Georgian National Museum, Tbilisi, Georgia e-mail: tea.jashashvili@usc.edu

B. A. Patel

Department of Integrative Anatomical Sciences, Keck School of Medicine,

University of Southern California, Los Angeles, CA, USA

e-mail: birenpat@usc.edu 
Keywords Paleoanthropology $\cdot$ Feet $\cdot$ Toes $\cdot$ Shoes $\cdot$ Phalanges $\cdot$ Hallux $\cdot$ Australopithecus $\cdot$ Homo

\section{Introduction}

The human lineage has evolved a pedal anatomy that facilitates an efficient striding bipedal gait. As the interface between the body and the substrate during gait, it is also the portion of the anatomy which is primarily responsible for the form and variation in footprints. Given that hominins have had a basically bipedal pelvic and leg anatomy since at least the early members of Australopithecus (Ward 2013), it is likely that variation in footprints would reflect a complex combination of pedal anatomy and the behaviours imposed on the foot. This short review is therefore intended to provide an overview of Pliocene and Pleistocene human pedal anatomy and variation, with respect to their implications for assessing footprints from the past. Particular focus is placed on the pedal digits, given the stability of the human tarsometatarsal skeleton once it became basically humanlike (or bipedal) in the earlier Pliocene (DeSilva et al. 2019).

The paleontological record for human foot evolution consists of isolated remains and a dozen partial pedal skeletons for the earliest phases, several of uncertain taxonomic affiliation. Middle Pleistocene associated feet derive from Dinaledi and Atapuerca-SH, there are half a dozen largely complete Middle Paleolithic pedal skeletons and then a relative abundance of them in the Upper Paleolithic. Only in the Middle and Upper Paleolithic, plus one Australopithecus specimen, are the pedal remains from associated skeletons. Therefore, for the Pliocene and Early Pleistocene, overall pedal anatomy is based on composites, often from diverse sites, whereas the later periods permit assessments from single individuals (DeSilva et al. 2019; Fig. 7.1). Isolated remains nonetheless fill out the record. The pedal remains from Aramis, Burtele and Liang Bua are not considered here, given their divergent configurations and their lack of association with footprints.

Individual points are not referenced in the discussion. For overall assessments, some of the key or more complete specimens and key aspects of the discussion, see Latimer et al. (1982), Susman (1983), Trinkaus (1983, 2005), Lordkipanidze et al. (2007), Zipfel et al. (2011), Ward (2013), Trinkaus et al. (2014, 2017), HarcourtSmith et al. (2015), Trinkaus and Patel (2016), Pablos et al. (2017), Fernández et al. (2018), McNutt et al. (2018) and DeSilva et al. (2019). For the earlier phases, DeSilva et al. (2019) provide an extensive review; for the later phases, see especially Trinkaus (1983), Trinkaus et al. (2014, 2017) and Pablos et al. (2017).

\section{The Tarsometatarsal Skeletons}

The tarsometatarsal (TMT) skeletons of all of these hominins indicate pedal structures that are similar to those of habitually unshod recent humans. They have compact and mediolaterally compressed posterior tarsals, with the calcaneal 


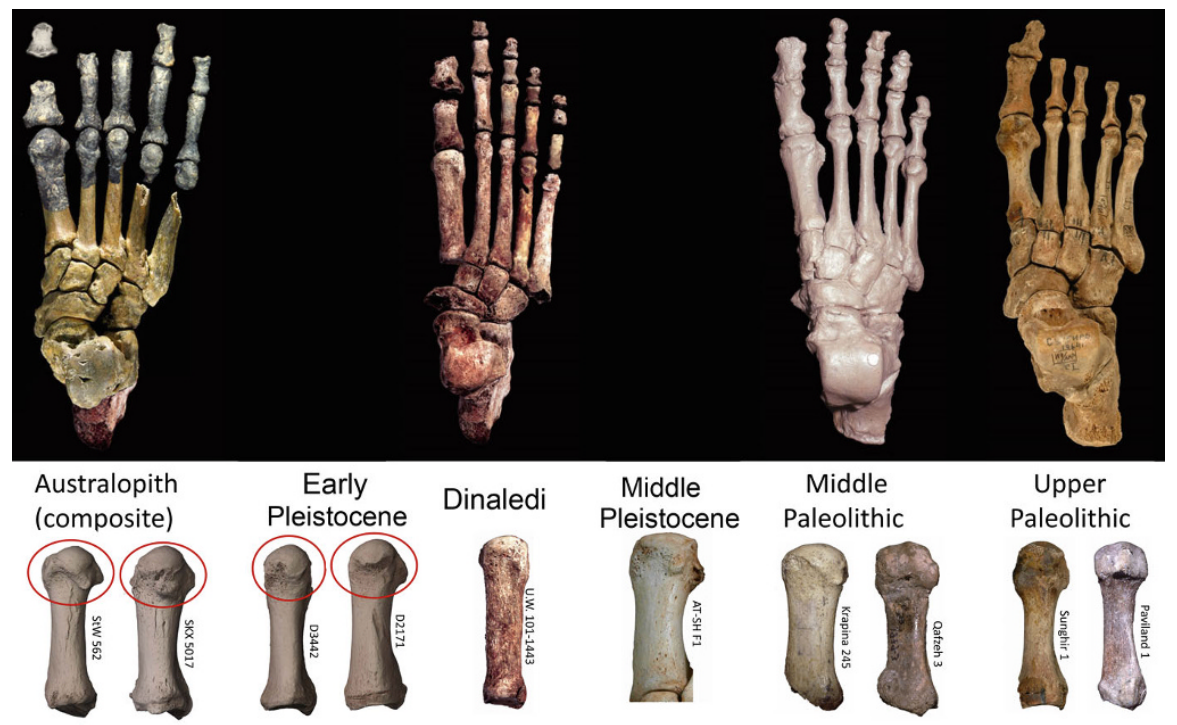

Fig. 7.1 Dorsal views of articulated pedal skeletons (above) and dorsal or plantar views of first metatarsals (below). The articulated pedal skeletons include an australopith composite (OH-8, A.L. 333-115, StW 617), Dinaledi Foot 1, Kiik-Koba 1 and Sunghir 1. The more bubous heads of the Sterkfontein, Swartkrans and Dmanisi MT-1 s are circled

tuberosity largely in line with the talar trochlea. They have low talar neck angles. The australopiths have large naviculocuboid facets, possibly reflecting modestly greater midtarsal mobility, but they are reduced to absent in Homo tarsals. All of them have fully adducted hallucal metatarsals despite some variation in angulation when the skeletal elements are articulated. The adduction is reflected in tarsometatarsal 1 articular orientations and the occasional metatarsal (MT) 1-2 facets; the mediolaterally curved and distally convex TMT-1 facets of some remains enhanced joint stability and were not abduction. They had fully formed longitudinal and transverse pedal arches, indicated by MT torsion (especially for rays 3 and 4) and oblique and horizontally oriented TMT articulations (especially for rays 3-5). In combination with the pedal arches, the metatarsophalangeal (MTP) articulations have mediolaterally oriented axes of rotation; for the MT-1, this resulted in perpendicular proximal and distal articular axes of rotation, permitting effective dorsiflexion at heel-off.

In this context, there was a variation in the degree of MT-1 medial divergence, overall pedal proportions, the relative sizes of articulations and other details of articular facets. It remains unclear to what extent these variations reflect body size (especially between australopiths and Homo), body proportions (especially ecogeographically in Middle and Late Pleistocene Homo), musculoskeletal hypertrophy and the effects of the presence/absence of habitual footwear use. None of these variations would have affected the basic kinesiology of the foot during a striding gait, beyond the considerable individual variation evident among recent humans. 


\section{The Hallux}

In the context of adducted halluces, there are contrasts between earlier and later hominins in two aspects, the shape of the MTP articulation and the presence/degree of distal phalangeal lateral deviation (hallux valgus). Both have functional implications.

The MT-1 heads of most Middle and Late Pleistocene MT-1s are indistinguishable from those of recent humans in being relatively large and modestly distally convex, with varying degrees of distal angulation caused by different degrees of dorsal extension of the intersesamoid crest (Fig. 7.1). The articulation is evidently adapted for transmitting elevated axial joint reaction forces with only modest degrees of abduction-adduction and dorsiflexion-plantarflexion. The Dinaledi MT-1s are similar to the other later Pleistocene ones in shape, but they have relatively smaller articulations. In contrast, the australopith and initial Pleistocene Homo MT-1s exhibit mediolaterally and dorsoplantarly bulbous heads (Fig. 7.1). Although fully compatible with predominantly axial joint reaction forces, their marked convexities imply increased mobility of the MTP-1 joint and/or increased joint stability relative to mediolateral forces on the distal hallux.

As a result of normal toeing-out during walking, most recent humans exhibit a lateral deviation of the distal hallucal phalanx (DP-1), or hallux valgus. All of the known Late Pleistocene and the Middle Pleistocene Atapuerca-SH DP-1s exhibit a similar lateral deviation (Fig. 7.2). In contrast, the few known DP-1s from australopiths, Early Pleistocene Homo and the Middle Pleistocene Dinaledi sample exhibit minimal lateral deviation of the DP-1. This is particularly evident in the complete OH-10 phalanx. Given that DP-1 lateral deviation is produced by differential medial versus lateral metaphyseal growth during development, from habitual forces on the hallux, the absence of this angulation in the earlier DP-1s implies little to no toeing-out among these hominins. Yet, at least OH-10 and the Dinaledi DP-1 exhibit axial torsion, which implies a humanlike toe-off.

\section{The Lateral Metatarsophalangeal Articulations}

During heel-off and the propulsive phase of a human stance, the ball of the foot and the toes are on the substrate, the pedal arch is raised and consequently the MTP articulations are substantially dorsiflexed. This distinctively human pedal posture has resulted, most prominently in recent humans, in a dorsal extension (or doming) of the metatarsal heads. The dorsal doming of the lateral metatarsal heads is present in all of the Middle and Late Pleistocene humans (including the Dinaledi remains). Additionally, the few Early Pleistocene Homo specimens appear to follow the recent human pattern. However, since this feature is variably present in the australopith MTs, it is unclear to what extent the australopith MTP articulations were habitually hyperdorsiflexed, as in a fully human heel-off. 


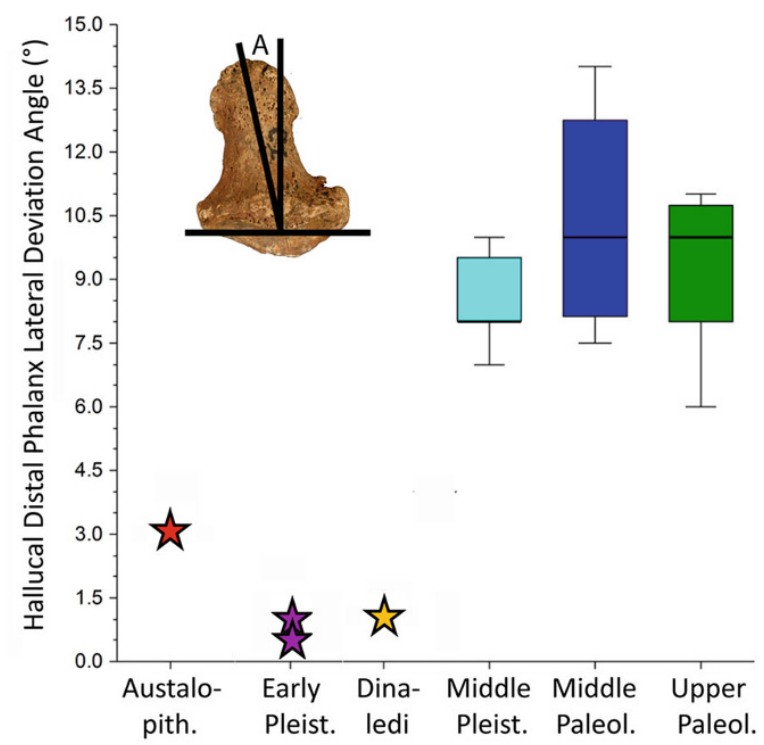

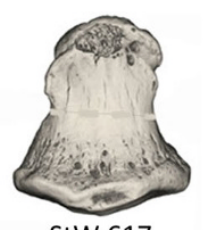

StW 617

Australopith

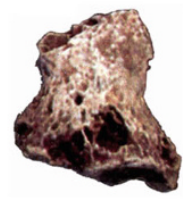

U.W. 101-1551

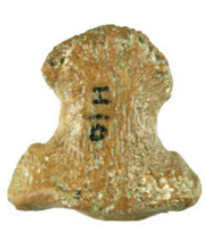

$\mathrm{OH}-10$

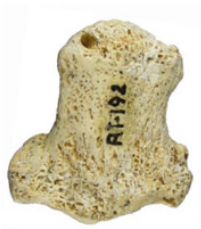

AT-SH 192

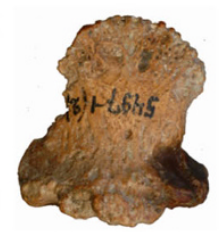

Kiik-Koba 1

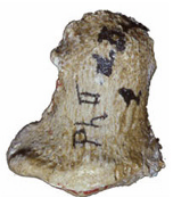

Krapina 252.1

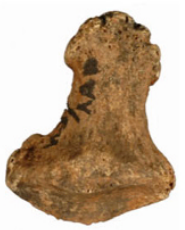

Sunghir 1

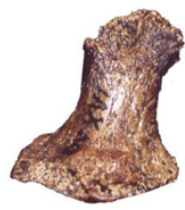

Dolní Věst 16

\section{Early Middle Middle Upper Pleistocene Pleistocene Paleolithic Paleolithic}

Fig. 7.2 Dorsal views of distal hallucal phalanges (below) and the distributions of DP-1 lateral deviation angles $(A)$ (above) 
MTP dorsiflexion at heel-off also produces a proximodorsal orientation (or canting) in recent human lateral proximal phalangeal metatarsal facets, especially of digits 2-4 (PP-2 to PP-4), such that the articular surfaces are oriented largely perpendicular to the resultant joint reaction forces. Given the more proximal position of the MT-5 head and the relative shortness of the fifth proximal phalanx (PP-5) in recent humans, this feature is less pronounced in the fifth MTP articulations.

Because of the difficulty in assigning isolated PP-2s to PP-4s to digit and australopith PP-5s to digit, it is necessary to pool these phalanges for comparaisons. All of the Middle and Late Pleistocene PPs follow the recent human pattern, with the lower articular angles deriving from PP-5s (Fig. 7.3). The same applies to the Middle Pleistocene Atapuerca-SH sample. The one Early Pleistocene phalanx, likely of Homo (SKX-16699), is among the more recent humans. The australopiths, although they have mostly dorsally oriented facets (in contrast to the plantar orientations of ape facets), exhibit angles that are substantially below those of Homo PPs, overlapping only the low values of some Late Pleistocene PP-5s.

\section{Lateral Proximal Phalanx Lengths and Shafts}

The lateral proximal pedal phalanges have generally uniform articular lengths through the Late Pleistocene and including the Atapuerca-SH Middle Pleistocene sample, with sample median lengths of 23-25 mm. The SKX-16699 Early Pleistocene Homo phalanx and the Dinaledi ones are shorter, averaging 18-20 $\mathrm{mm}$ in length, given smaller body sizes. However, the australopith ones, although variable, are considerably longer, with a median length of $27-28 \mathrm{~mm}$, despite their small bodies. When compared to estimated body mass from femoral head diameters (Fig. 7.4) (by individual for the Late Pleistocene and A.L. 288-1 and by each phalanx to every body mass estimate for the other samples), the Pleistocene Homo samples are very similar. The australopith PPs, with their generally smaller body sizes, are substantially relatively longer (even ignoring the few, probably inappropriate, high ratios). A few of the australopith ratios overlap the Homo ones, and two of the Dinaledi ones are also relatively high. But there is nonetheless a substantial dichotomy between the australopith and Homo relative phalangeal lengths.

The longer australopith proximal phalanges are associated with a suite of related diaphyseal features that contrast with those of later Homo (Figs. 7.3 and 7.4). The Homo phalanges exhibit largely dorsally straight diaphyses, ovoid-shaped midshafts and small flexor sheath ridges located on the medial and lateral midshafts (although the Dinaledi and SKX-16699 PPs have slight dorsal convexities). The australopith phalanges are distinctly curved on their dorsal margins. They have prominent flexor sheath crests that are on the medioplantar and lateroplantar diaphysis along the distal halves of the shafts. The sizes and positions of these flexor sheaths are a product of having more curved diaphysis and hence greater plantarly directed forces on the sheaths, likely arising from the stronger contraction of the long pedal digital flexor 
Fig. 7.3 Lateral views of lateral proximal pedal phalanges (below) and distributions of proximal articular angles. The angle is relative to the mid-articular axis and is generally lower than the canting angle (which inappropriately uses the plantar surface as the plane of reference). The Middle Pleistocene

Atapuerca-SH sample has angles similar to the Late Pleistocene samples (Fig. 7.4)
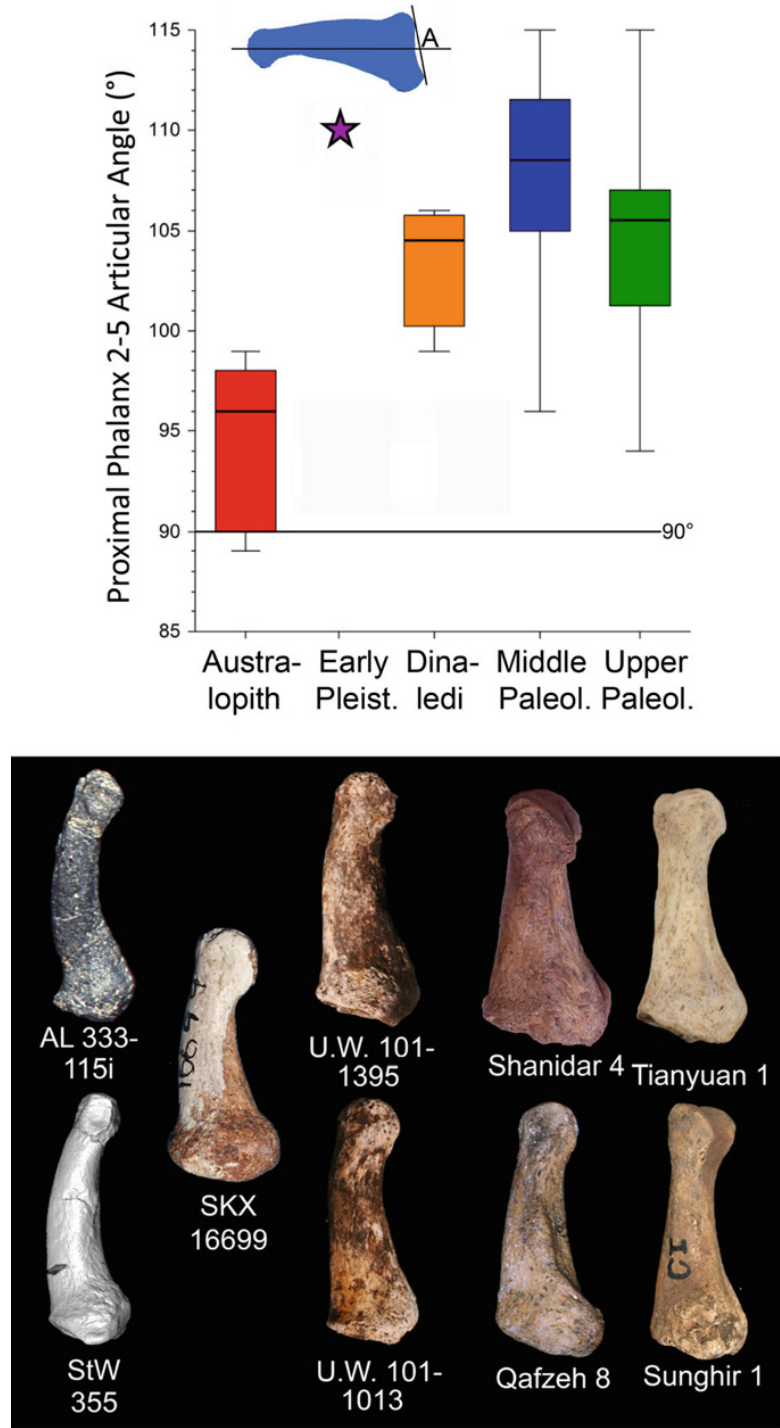

$\begin{array}{ll}\text { Austra- Early Dinaledi } & \text { Middle Upper } \\ \text { lopith Pleist. } & \text { Paleol. Paleol. }\end{array}$

muscles. These specific features cause the midshafts to appear semicircular in crosssectional shape. The phalanges are also mediolaterally expanded more distally, giving the diaphysis a proximally waisted appearance in dorsal view. However assessed, the australopith lateral proximal pedal phalanges imply some degree of prehension, albeit markedly less than the much longer ones of the great apes. 

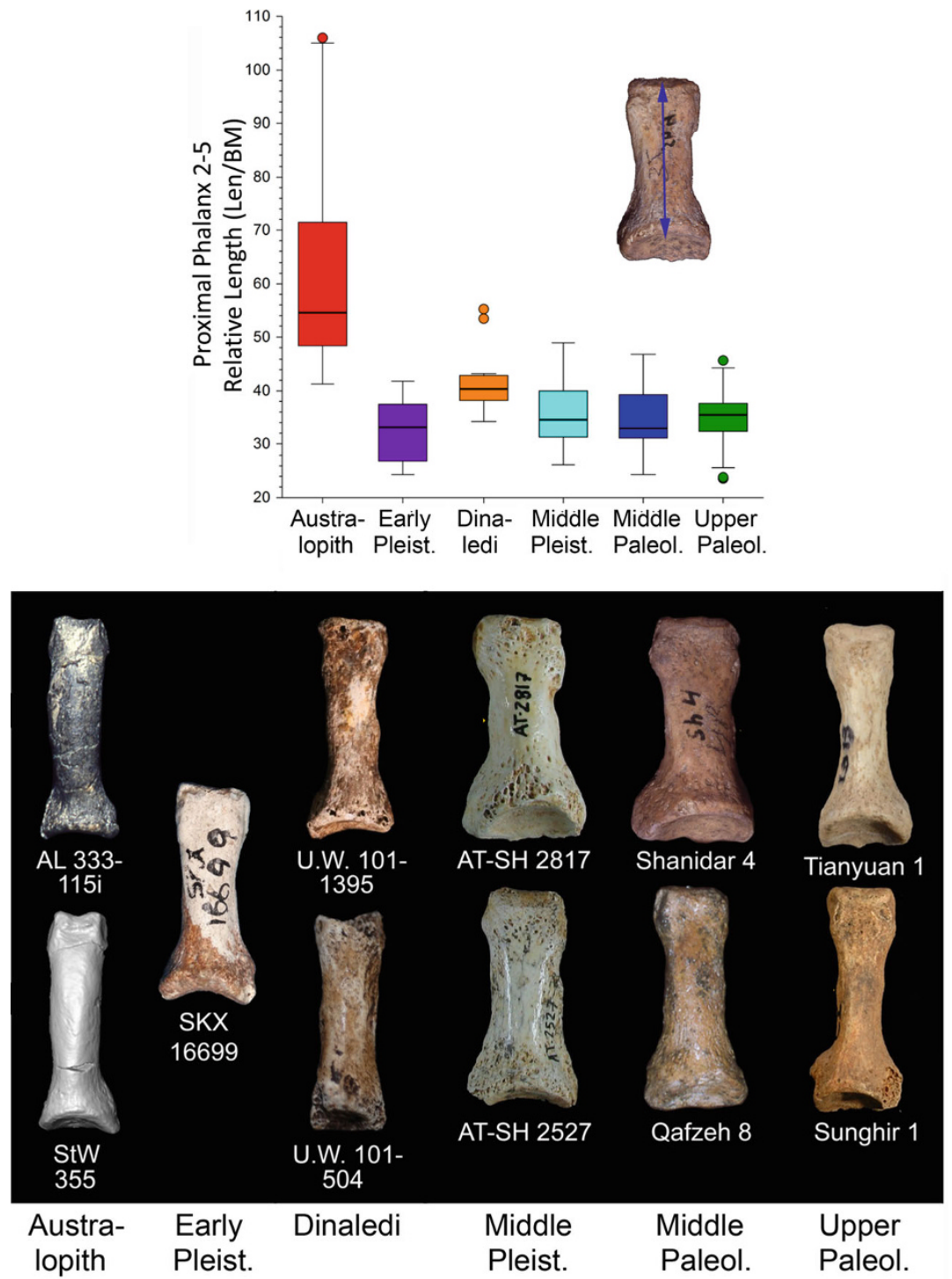

Fig. 7.4 Dorsal views of lateral proximal pedal phalanges (below) and articular length/estimated body mass (as a percentage) (above). For the Middle and Upper Paleolithic samples and A.L. 288-1, the comparisons are within individuals. For the remainder of the earlier samples, given the absence of associated phalanx lengths and body mass estimates, each phalangeal length is divided by each femoral head-based body mass estimate available for the appropriate sample. For the two Middle Pleistocene samples (Dinaledi and Atapuerca-SH), the comparisons are within site. For the StW, DNH and A.L. phalanges, the body mass estimates are from the femora attributed to Au. africanus, $P$. robustus and $A u$. afarensis respectively. For SKX-16699, the body mass estimates are for those attributed to early Homo (sensu stricto). For these reasons, and the pooling of lengths from rays 2 to 5 , the box plots for the earlier samples (especially the australopiths) exhibit considerably greater variation than is indicated by the phalanges themselves 


\section{Proximal Pedal Phalanx Diaphyseal Hypertrophy}

It is also possible to assess the relative degrees of hypertrophy, or robustness, of the lateral pedal phalanges, again pooling those from digits 2 to 5 and comparing those phalanges without an individually associated body mass to the range of body masses available for the appropriate sample (Fig. 7.5). To maximize sample sizes, midshaft polar moments of area are estimated from the diaphyseal diameters using ellipse formulae, and they are scaled using articular length times estimated body mass. The resultant values (Fig. 7.5) provide a large range for the australopiths, low values for the Early Pleistocene SKX-16699, higher values for the Dinaledi sample and intermediate and similar ranges for the Middle Pleistocene and Middle Paleolithic samples. Given the extensive overlap of these samples and the necessity to associate almost all of the pre-Middle Paleolithic ones by sample rather than by individual, there is probably little significance in the variations across these fossil samples.

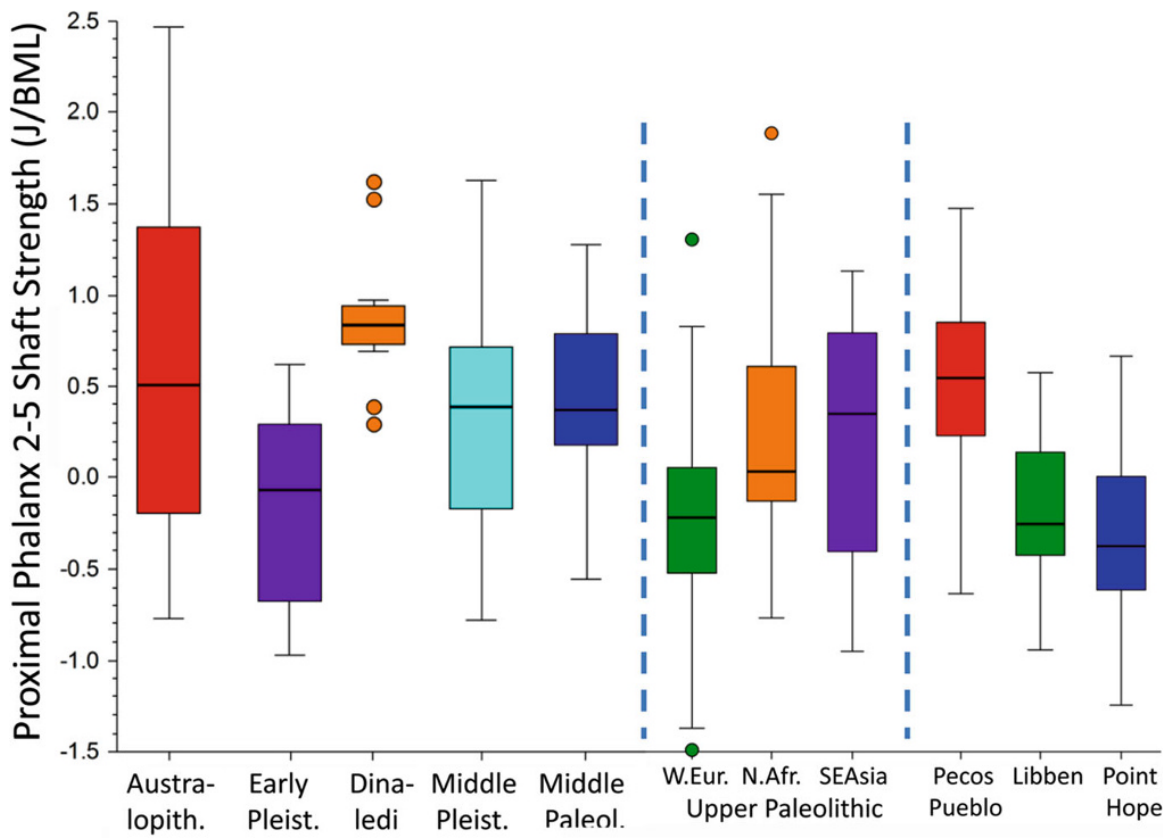

Fig. 7.5 Comparisons of midshaft relative strength across the paleontological samples and three recent Native American samples. Polar moments of area (J/Ip) are computed using standard ellipse formulae from the diaphyseal diameters, modelling the diaphysis as solid, and each is relative to the estimated body mass times phalangeal articular length (see Trinkaus and Patel 2016). As in Fig. 7.4, Late Pleistocene and recent phalanges, plus that of A.L. 288-1, are scaled by individual. The others are scaled to each of the body mass estimates for the appropriate sample. The Upper Paleolithic sample is subdivided regionally, and the recent human samples represent prehistoric Native Americans who were habitually unshod (Pecos Pueblo), shod (Point Hope) and variably shod (Libben) 
In the assessment of the Upper Paleolithic phalanges, however, there is substantial interregional variation. The western Eurasian sample has relatively gracile phalanges, whereas the North African and especially the Southeast Asian one have more robust phalanges. In contrast, there is little difference across these samples in overall lower limb robustness. If these three samples are compared to ecogeographically separate Native American prehistoric samples, however, a pattern emerges. Across the Native American samples, the habitually unshod Pecos Pueblo (New Mexico) sample has robust phalanges, similar to Middle Pleistocene and Middle Paleolithic ones. The habitually shod Inuit Point Hope (Alaska) sample has relatively gracile ones, similar to the western Eurasian Upper Paleolithic sample. And the geographically intermediate Libben (northern Ohio) sample is modestly less gracile. Given that these three samples of Native Americans were similarly robust in their lower limbs, the variation in lateral pedal phalangeal hypertrophy reflects the degrees to which their lateral toes were protected by differences in the habitual use of footwear. If the framework from these Native Americans is then applied to the Upper Paleolithic samples, the inference is that the western Eurasian sample was habitually shod, the Southeast Asian one was often barefoot and the North African sample was intermediate but closer to the Southeast Asian one in the use of protective foot wear.

\section{Implications for Pliocene and Pleistocene Footprints}

The tarsometatarsal configurations of all of these Pliocene and Pleistocene pedal remains are therefore basically similar to those of recent humans, despite minor variations in size, proportions, articular details and musculoligamentous hypertrophy. They therefore imply that the primary forms of the footprints attributed to australopiths or members of the genus Homo should be similar. Given the high degree of variation in unshod footprint form within and across individuals among recent humans, due to normal ranges of pedal size and proportions, the variation in digital separation, degrees of toeing out during walking and variable pedal arch height, overlain by idiosyncratic variation in walking patterns, terrain and (of course) substrate characteristics, all of these hominins should have made footprints which were generally similar.

The areas of functional contrast in the pedal remains involve the digits. The australopiths and (to varying degrees) initial Homo digital remains indicate greater hallucal mobility and/or lateral forces on the hallux, a lack of hallux valgus (hence little toeing out), longer lateral phalanges and lateral phalanges which were less dorsiflexed in the later stages of the stance phase. The expectation would therefore be that australopith footprints, relative to those of later Homo, would exhibit normal human heel, arch and ball imprints, but that they would contrast in having less toeing out of the print (or more anteroposterior orientation of the footprint) and especially distally extended and deeper impressions from the lateral toes. 
The one axis of variation among later Pleistocene humans is the reduction in lateral phalangeal robustness among the western Eurasian Upper Paleolithic humans and to a lesser extent among the North African ones. Especially compared to the Middle Pleistocene and the Middle Paleolithic samples, the implication is that there was a marked increase in the use of protective foot wear among these Upper Paleolithic human populations. Paleolithic footwear is not known, although at least one sample (the early Upper Paleolithic Sunghir one from northern Russia) exhibits both body decoration implying leggings/boots and extremely gracile lateral phalanges, indicating their habitual use of protective boots. Interestingly, almost all of the footprints known from Upper Paleolithic Eurasia are of unshod people, whether of children or adults. Were these people more often barefoot than their pedal phalanges and their cold temperate to glacial environments imply? Were they removing footwear to walk more securely in the karstic systems in which the footprints are primarily found? Or is there a bias in our footprint sample, such that the distinctively human barefoot ones are readily recognized, but the more amorphous ones that would be created by soft boots remain unrecorded?

Acknowledgements S. Potze and B. Zipfel provided support and access to the SK, SKX and StW collections at the Ditsong National Museum of Natural History and at the Evolutionary Studies Institute, University of the Witwatersrand, South Africa, respectively. We thank Dmanisi research team for access to Dmanisi collection at the Dmanisi Museum-Reserve, Georgian National Museum. We thank the Evolutionary Studies Institute, the University of the Witwatersrand's Microfocus X-ray Computed Tomography Facility for facilitating access to the high-resolution micro-CT data used for figure presentations. The Atapuerca-Sima de los Huesos images and comparative data have been made available by A. Pablos, and the Dinaledi images were provided by W. Harcourt-Smith. Access to Late Pleistocene human remains has been provided by a large number of individuals and curating institutions, and L.L. Shackelford and G. Apfeld assisted with the collection of the recent human data. To all of these individuals and institutions, we are immensely grateful.

\section{References}

DeSilva, J., McNutt, E., Benoit, J., \& Zipfel, B. (2019). One small step: A review of PlioPleistocene hominin foot evolution. American Journal of Physical Anthropology, 168(S67), 63-140. https://doi.org/10.1002/ajpa.23750.

Fernández, P. J., Mongle, C. S., Leakey, L., Proctor, D. J., Orr, C. M., Patel, B. A., et al. (2018). Evolution and function of the hominin forefoot. Proceedings of the National Academy of Sciences USA, 115, 8746-8751. https://doi.org/10.1073/pnas.1800818115.

Harcourt-Smith, W. E. H., Throckmorton, Z., Congdon, K. A., Zipfel, B., Deane, A. S., Drapeau, M. S. M., et al. (2015). The foot of Homo naledi. Nature Communications, 6, 8432. https://doi. org/10.1038/ncomms 9432 .

Latimer, B. L., Lovejoy, C. O., Johanson, D. C., \& Coppens, Y. (1982). Hominid tarsal, metatarsal, and phalangeal bones recovered from the Hadar Formation: 1974-1977 collections. American Journal of Physical Anthropology, 57, 701-719.

Lordkipanidze, D., Jashashvili, T., Vekua, A., Ponce de León, M. S., Zollikofer, C. P. E., Rightmire, G. P., et al. (2007). Postcranial evidence from early Homo from Dmanisi, Georgia. Nature, 449, 305-310. 
McNutt, E. J., Zipfel, B., \& DeSilva, J. M. (2018). The evolution of the human foot. Evolutionary Anthropology, 27, 197-217. https://doi.org/10.1002/evan.21713.

Pablos, A., Pantoja, A., Martínez, I., Lorenzo, C., \& Arsuaga, J. L. (2017). Metric and morphological analysis of the foot in the Middle Pleistocene sample of Sima de los Huesos (Sierra de Atapuerca, Burgos, Spain). Quaternary International, 433A, 103-113. https://doi.org/10.1016/ j.quaint.2015.08.044.

Susman, R. L. (1983). Evolution of the human foot: Evidence from Plio-Pleistocene hominids. Foot and Ankle, 3, 365-376. https://doi.org/10.1177/107110078300300605.

Trinkaus, E. (1983). Functional aspects of Neandertal pedal remains. Foot and Ankle, 3, 377-390.

Trinkaus, E. (2005). Anatomical evidence for the antiquity of human footwear use. Journal of Archaeological Science, 32, 1515-1526. https://doi.org/10.1016/j.jas.2005.04.006.

Trinkaus, E., \& Patel, B. A. (2016). An Early Pleistocene human pedal phalanx from Swartkrans, SKX 16699, and the antiquity of the human lateral forefoot. Comptes Rendus Palevol, 15, 978-987. https://doi.org/10.1016/j.crpv.2016.07.003.

Trinkaus, E., Buzhilova, A. P., Mednikova, M. B., \& Dobrovolskaya, M. V. (2014). The people of Sunghir: Burials, bodies and behavior in the earlier Upper Paleolithic. New York: Oxford University Press.

Trinkaus, E., Wojtal, P., Wilczyński, J., Sázelová, S., \& Svoboda, J. (2017). Palmar, patellar and pedal human remains from Pavlov. PaleoAnthropology, 2017, 73-101. https://doi.org/10.4207/ pa.2017.art106.

Ward, C. V. (2013). Postural and locomotor adaptations of Australopithecus species. In K. E. Reed, J. G. Fleagle, \& R. E. Leakey (Eds.), The paleobiology of Australopithecus (pp. 235-245). New York: Springer. https://doi.org/10.1007/978-94-007-5919-0_16.

Zipfel, B., DeSilva, J. M., Kidd, R. S., Carlson, K. J., Churchill, S. E., \& Berger, L. R. (2011). The foot and ankle of Australopithecus sediba. Science, 333, 1417-1420. https://doi.org/10.1126/ science.1202703.

Open Access This chapter is licensed under the terms of the Creative Commons Attribution 4.0 International License (http://creativecommons.org/licenses/by/4.0/), which permits use, sharing, adaptation, distribution and reproduction in any medium or format, as long as you give appropriate credit to the original author(s) and the source, provide a link to the Creative Commons license and indicate if changes were made.

The images or other third party material in this chapter are included in the chapter's Creative Commons license, unless indicated otherwise in a credit line to the material. If material is not included in the chapter's Creative Commons license and your intended use is not permitted by statutory regulation or exceeds the permitted use, you will need to obtain permission directly from the copyright holder.

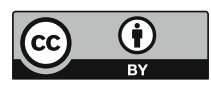

